Ron Levy, M.D., Ph.D.

Department of Physiology,

University of Toronto,

Toronto, Canada

Andres M. Lozano, M.D., Ph.D.

Department of Surgery,

Division of Neurosurgery, and

The Toronto Western Research Institute,

University of Toronto,

The Toronto Western Hospital,

Toronto, Canada

William D. Hutchison, Ph.D.

Departments of Physiology and Surgery, Division of Neurosurgery, and

The Toronto Western Research Institute,

University of Toronto,

Toronto, Canada

Jonathan O. Dostrovsky, Ph.D.

Department of Physiology and,

The Toronto Western Research Institute,

The Toronto Western Hospital,

University of Toronto,

Toronto, Canada

Reprint requests:

Jonathan O. Dostrovsky, Ph.D.,

Department of Physiology,

Room 3302, Medical Sciences Building,

1 King's College Circle

University of Toronto,

Toronto, Ontario, Canada M5S 1A8.

Email: j.dostrovsky@utoronto.ca

Received, December 8, 2005. Accepted, December 3, 2006

\title{
Dual Microelectrode TeChNiQue for DeeP Brain Stereotactic Surgery in Humans
}

OBJECTIVE: To improve functional stereotactic microelectrode localization of small deep brain structures by developing and evaluating a recording system with two closely separated independently controlled microelectrodes.

METHODS: Data were obtained from 52 patients using this dual microelectrode technique and 38 patients using the standard single microelectrode technique for subthalamic nucleus localization in patients with Parkinson's disease.

RESULTS: There was a decrease in the incidence of noncontributory trajectories, defined as a single penetration made by the pair of closely spaced parallel microelectrodes, owing to microelectrode failure (from $7.2 \%$ to $<1 \%$ ), an improved localization and verification of nuclear borders, and a significant decrease in the number of trajectories used to localize the subthalamic nucleus from a median of three to two per initial operative side $(P<0.001)$. The technique also provides the novel opportunity to examine population activity by correlating the discharge between two closely spaced simultaneously recorded neurons and can be used to monitor the electrophysiological effects of local electrical stimulation or microinjections of pharmacological agents.

CONCLUSION: Our experience indicates that the use of two closely spaced microelectrodes improves the utility of microelectrode localization in minimally invasive functional neurosurgery.

KEY WORDS: Deep brain stimulation, Microelectrode recordings, Parkinson's disease, Stereotactic functional neurosurgery, Subthalamic nucleus

Neurosurgery 60[ONS Suppl 2]:ONS-O-ONS-0, 2007

DOI: 10.1227/01.NEU.0000255389.85161.03

M icroelectrode techniques are commonly used in functional stereotactic neurosurgery to provide physiological localization in conjunction with initial targeting by magnetic resonance imaging (MRI) $(2,17,18,39,42,49)$. Together, microelectrode recording and electrical stimulation provide precise delineation of subcortical structures, such as the subthalamic nucleus (STN), globus pallidus internus (GPi), and thalamic nuclei, for the treatment of a variety of neurological disorders $(5,23,33,35,47,48)$. Neuronal recordings from these structures have added considerably to our understanding of basal ganglia pathophysiology in patients with Parkinson's disease (PD) (22, 24, $27,31,45)$.

However, the disadvantages of microelectrode recordings include an increased intraoperative time, the necessity of a high degree of technical support, the fragility of the microelectrodes, and the requirement for multiple trajectories that may further damage cortical and subcortical tissue. In addition, the data obtained represents only information collected from single neurons, not correlated population activity. Therefore, motivated by a need to improve the efficiency of microelectrode localization, to keep the surgery minimally invasive, and gather as much information as possible to determine a meaningful functional localization, we discuss our experience with dual microelectrode recordings for STN localization in patients with PD. We present a versatile head stage design that allows us to record from two closely spaced, independently controlled microelectrodes and demonstrate an improved utility over single microelectrode techniques. 


\section{METHODS}

\section{Head Stage Assembly, Microelectrodes, and Cannulas}

A photograph of the dual microdrive head stage assembly is F1 shown in Figure 1. This assembly was designed to fit the standard Leksell G stereotactic frame (Elekta Instruments, Stockholm, Sweden) and consists of a platform that holds two hydraulic microdrive slave-cylinder units and a detachable guide tubes assembly. Each microdrive has a range of motion of $21 \mathrm{~mm}$, with the platform allowing for $25 \mathrm{~mm}$ of clearance. The two inner guide tubes were constructed by soldering two 23gauge, thin walled stainless steel tubes (HTX-23TW; Small Parts Inc., Miami Lakes, FL) side by side. These were then set in the guide tubes assembly in a position mediolateral to each other relative to the patient. The dual inner guide tubes fit easily into the standard stereotactic frame outer guide tube, which, in our setup, was constructed from 17 gauge stainless steel tubing (HTX-17; Small Parts Inc.). The distal ends of the inner guide tubes were flush with the outer guide tube. As seen in Figure 1, a gradual 30-degree curve in one of the guide tubes allowed for adequate separation of the microdrive units. This feature did not cause any noise owing to friction as the microelectrode was driven down. The configuration of the inner guide tubes set the center of each 23-gauge guide tube at approximately $300 \mu \mathrm{m}$ off the central axis of the stereotactic frame outer guide tube (see Figure 1)). The microelectrodes were parallel and were separated by a mediolateral distance of $600 \mu \mathrm{m}$ and by 0 to $20 \mathrm{~mm}$ in the superior-inferior direction. The dual microdrive assembly is quite light as it is made from aluminum and did not cause any problems (e.g., distortion of the frame).

For all patients in this study, identical microelectrode tips were used in either single or dual recording methods. For dual record-

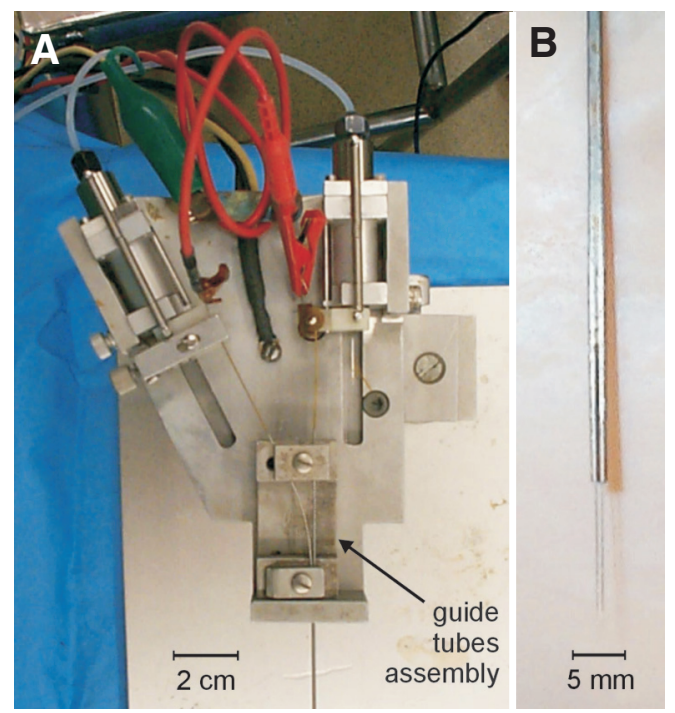

FIGURE 1. A, head stage and detachable guide tubes assembly. B, microelectrodes extending from the distal end of dual guide tubes. Note that the microelectrodes were oriented mediolaterally with respect to the patient and were centered approximately $300 \mu \mathrm{m}$ off the center axis of the stereotactic frame guide tube. ings, parylene- $C$ coated tungsten microelectrodes with tip dimensions of $25 \mu \mathrm{m}$ (we300325A, Microprobe) were proximally AQ:1 stripped of $2 \mathrm{~cm}$ of insulation and elongated by backing the microelectrodes into a 30-cm length of 30-gauge stainless steel tubing (HTX-30, Small Parts Inc.), leaving $10 \mathrm{~mm}$ exposed distally. Polymide tubing was used to insulate the stainless steel tubing (\#28, Micro ML) and was joined to the microelectrode AQ:2 using epoxy resin. Microelectrodes used in the single microelectrode setup were similarly constructed with 25-gauge stainless steel tubing (HTX-25, Small Parts Inc.) and appropriately sized polymide tubing (\#23, Micro ML). All microelectrodes were plated with gold and platinum to a final impedance of approximately $100 \mathrm{Kohms}$ at $1000 \mathrm{~Hz}$. At the proximal end of the microelectrode, the polymide tubing was stripped by $1 \mathrm{~cm}$ to create a site for connection to the amplifier head stage.

Lastly, we sometimes used the dual guide tube setup to perform macrostimulation, record local field potential (LFP) activity, or to locally inject drugs simultaneously with single microelectrode recordings. These could all be accomplished by using a cannula constructed from 30-gauge stainless steel tubing (HTX30, Small Parts Inc.) and insulated by polymide tubing (\#28, Micro ML) instead of one of the microelectrodes. For LFP recordings and macrostimulation, $1 \mathrm{~mm}$ of polymide tubing was removed at the distal end of the cannula. This length of exposure was chosen as the best trade off between the dimensions of the deep brain stimulator (DBS) leads used for chronic stimulation (diameter, $1.27 \mathrm{~mm}$; length, $1.52 \mathrm{~mm}$ ) and small enough to record discrete LFPs in a relatively small nucleus (maximum, approximately $10 \times 6 \mathrm{~mm}$ in the parasagittal plane). An external stimulus generator connected to an isolated current source was used to perform macrostimulation using the cannula (stimulus isolator A360; World Precision Instruments, Sarasota, FL). For injection of drugs, a 2-cm length of 23-gauge tubing (HTX-23, Small Parts Inc.) was soldered at the proximal end to provide for a tight fit with polyethylene tubing that was connected to a $25 \mu \mathrm{l}$ Hamilton syringe (Hamilton Co., Reno, NV). Electrophysiological and clinical data for LFP recordings and drug injections in the STN have been described previously $(28,32)$.

\section{Intraoperative Recording Methods}

Detailed descriptions of operative procedures have been described elsewhere $(26,34)$. Briefly, a Leksell stereotactic frame was installed under local anesthesia. MRI or computed tomographic scanning was used to locate the frame coordinates for the anterior and posterior commissures. A digitized stereotactic atlas plate of a sagittal map (46) at the appropriate laterality for the target that was adjusted to match each patient's intercommissural distance was calculated and displayed on a computer screen and used to determine the frame coordinates of the target. The target for the first track was a site approximately $1 \mathrm{~mm}$ dorsal to the ventral border of the STN at the $12 \mathrm{~mm}$ lateral plane. A small hole was then made in the cranium under local anesthesia, and physiological mapping of neuronal activity was performed.

Single unit neuronal activity recorded from each microelectrode was amplified, high-pass filtered (200-300 Hz), and monitored on a loudspeaker and displayed using two dedicated 
GS3000 systems (Axon Instruments, Foster City, CA.). Both microelectrodes shared a common ground with the amplifiers (black wire in Figure 1) and the entire head stage was further grounded (green wire in Figure 1) to the Axon instrument chassis. Identification of nuclear boundaries was made by finding well-isolated single neurons and background multiunit activity with characteristic firing properties typical of either the STN or the substantia nigra pars reticulata ( $\mathrm{SNr}$ ), as described previously (23). Patients included in this study were those undergoing bilateral or unilateral microelectrode mapping of the STN for the insertion of DBS electrodes. This was performed using either a standard single microelectrode microdrive or the dual microelectrode microdrive described above. For the latter technique, only patients in whom both microelectrodes were used throughout the entire surgery were included. In this report, a "trajectory" is defined as a single penetration made by the pair of closely spaced parallel microelectrodes, i.e., the continuation of the axis of the 17 gauge outer guide tube through which the inner guide tube is located and through which the microelectrodes pass. A "track" is defined as the path of an individual microelectrode. Electrophysiological features were documented intraoperatively by noting and plotting the firing and receptive field characteristics of the neurons recorded in the pair of microelectrode tracks in the one trajectory. Dual recordings were used in 52 patients, whereas single microelectrodebased localization was used in 38 patients.

\section{RESULTS}

The typical use of the dual recordings involved moving each microelectrode past the other stationary microelectrode, allowing us to record from single neuron pairs that were in a staggered position. Recordings were quite stable when one microelectrode was moved past the other; neurons were rarely "lost" at the stationary microelectrode. The use of two microelectrodes allowed us to independently sample twice as many neurons in each trajectory. However, our effort was concentrated on recording from the most well-isolated and stable neurons in each track, thereby bypassing those neurons with low signal-to-noise ratio. Qualitatively, there was a minor increase in the time required to explore each trajectory.

A distinct advantage of the dual electrode technique is that if a microelectrode failed (i.e., did not satisfactorily record single unit activity), the second microelectrode could be used as a backup for what would otherwise be a noncontributory track. Microelectrode tips are fragile and liable to be damaged and may, therefore, result in unreliable information collection from a track. This occurrence can sometimes be detected immediately by a very high or low impedance, and the electrode can be replaced. In other cases, it may not be clear whether the lack of recordings are the result of a defective electrode (despite normal impedance) or passage through white matter or damaged brain. Also, in some cases, the presence of injury discharge of neurons before the spikes are wellisolated or a poor signal-to-noise ratio suggests a defective electrode. In these cases, repeating the track with a new electrode would be time consuming and may not yield good data owing to its passage down the previous electrode penetration and, thus, is not advisable. In such cases, we would usually proceed with the other microelectrode. Under these circumstances, this technique was more time efficient than the standard setup because we were able to quickly verify our findings using the second microelectrode, thereby avoiding possible additional electrode penetrations owing to possible false-negative data or having to remove the head stage apparatus to replace the microelectrode in cases where the electrode was suspected to be malfunctioning. The total number of trajectories performed in the dual microelectrode setup was 118; hence, the total number of microelectrode tracks was 236. Seven tracks in one guide tube and 10 tracks in the other were deemed unreliable, resulting in an overall microelectrode "failure" rate of $7.2 \%$. There were no instances of both microelectrodes being unreliable in the same trajectory. The expected theoretical failure rate using the dual technique is less than $1 \%$.

The distances of borders identified with individual microelectrodes to the initial dorsal-ventral target locations are F2 shown in Figure $2 A$. There were a total of 444 borders identified with individual microelectrodes. The dorsal and ventral borders of the STN were located a median of 3.0 and $-0.2 \mathrm{~mm}$ from the initial target, respectively. The dorsal border of the $\mathrm{SNr}$ was located a median of $-2.5 \mathrm{~mm}$ from the initial dorsalventral STN target. The use of a second microelectrode allowed the confirmation of electrophysiological landmarks such as nuclear borders. The instances of individual trajectories in which borders were identified on both or neither microelectrodes (i.e., similar findings) were compared with the instances in which a border was found on one microelectrode but not the other. Table 1 shows that there were similar findings on both microelec- T1 trodes in approximately $95 \%$ of the trajectories for the dorsal and ventral border of the STN. In the case of the dorsal and ventral STN borders, there was a low incidence of cases in which a border was identified on one microelectrode but not the other (approximately 5\%). There was no difference regarding which microelectrode was in disagreement. Figure $2 B$ shows the dorsalventral distances between identified borders when dual microelectrodes were used. There were 77, 74, and 56 pairs of borders identified with both microelectrodes for the dorsal STN, ventral STN, and dorsal SNr borders, respectively. The mean separation in identified borders was approximately $0.6 \mathrm{~mm}$, and there was no difference in separation between the three identified borders $(P=0.856$, one-way analysis of variance on ranks).

Figure 2C compares the number of trajectories used to localize the STN with the dual and single techniques. In the case of bilateral recordings, only data from unilateral exploration and the initial side of the brain (typically the right side) was used. There was a significant difference of a median of two versus three trajectories (mean, 2.3 versus 3.6 trajectories) for dual and single recordings, respectively $(P<0.001$, Mann-Whitney Rank Sum Test). Figure 2D displays this information as a function of patient chronological order. It can be seen that there was a decrease in the number of trajectories required to accurately localize the STN. We did not obtain postoperative CT scans on patients but the incidence of symptomatic postoperative hemorrhage using either technique was similar (1 to $2 \%$ ). 


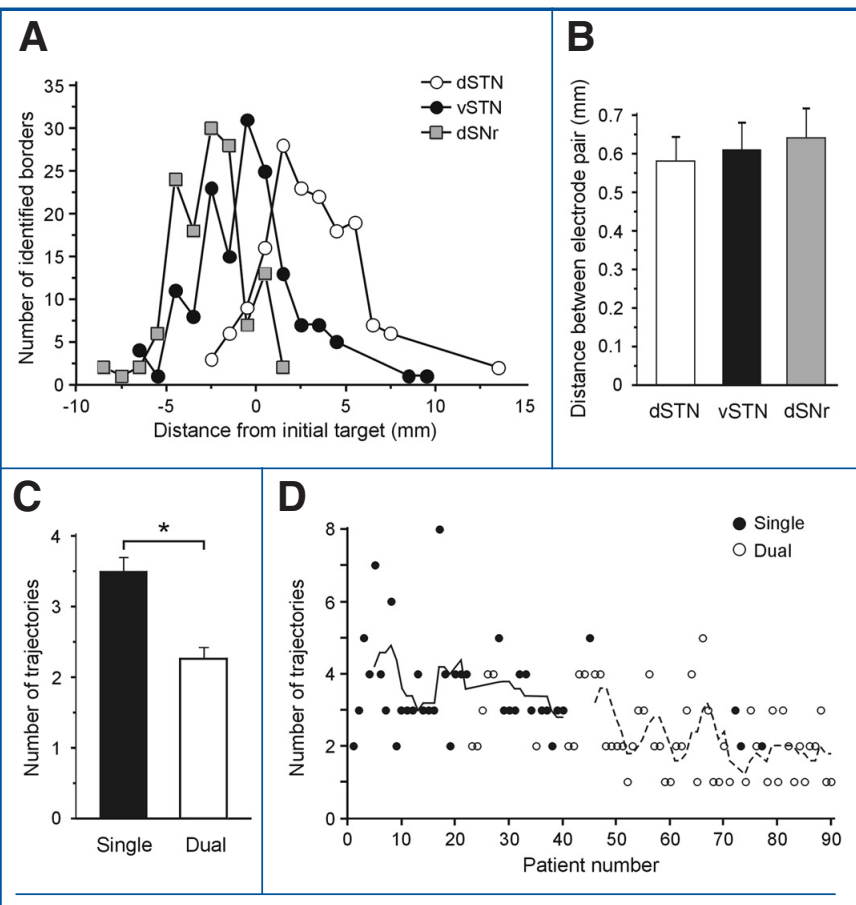

FIGURE 2. A, line graph showing the distances from the initial dorsalventral target locations as derived from MRI to the nuclei borders as identified with individual microelectrodes. B, bar graph showing the distances between the borders identified on each microelectrode (mean and standard error of the mean) when dual recordings were used $(P=0.856$, one-way analysis of variance on ranks). C, bar graph showing that there was a significant decrease in the number of trajectories used to localize the STN when dual recordings were used. This bar graph shows the mean and standard error of the mean (asterisk, $P<0.001$, Mann-Whitney rank sum test). D, line graph showing the number of trajectories needed to localize the STN using dual versus single microelectrode recordings as a function of patient chronological order. The solid line represents the average number of trajectories using the single technique (excluding Patients 23-27 and 35, who had dual recordings) for the current and four previous patients. The dashed line represents the average number of trajectories using the dual technique (excluding Patients 45, 72, 73, and 77, who had single recordings) for the current and four previous patients. dSTN, dorsal STN border, vSTN, ventral STN border, dSNr, dorsal SNr border.
Lastly, the use of two independently controlled microelectrodes allowed for the experimental characterization of population activity and the analysis of neuronal responses to local electrical stimulation. Figure $3 A$ displays a schematic of a trajec- F3 tory through the STN of a single patient. Autocorrelograms of some individual STN neurons displayed oscillations at approximately $20 \mathrm{~Hz}$ (not shown) and were designated as STN $\beta$ cells (i.e., neurons displaying $\beta$ band $13-30 \mathrm{~Hz}$ oscillations). Crosscorrelograms of oscillatory neuron pairs demonstrate that an approximate $20 \mathrm{~Hz}$ in-phase synchronization is present in a group of dorsally located STN neurons. Neuron pairs displaying 13 to $30 \mathrm{~Hz}$ oscillatory in-phase synchronization were similarly clustered in the dorsal aspect of the STN in other patients examined. Oscillatory synchronization was not encountered in pairs of SNr neurons. Figure 3B shows the response of STN and $\mathrm{SNr}$ neurons to local electrical stimulation in four patients. After the stimulation artifact, a period of inhibited activity can be seen in the STN and SNr for both high $(300 \mathrm{~Hz})$ and low frequency stimulation (20 and $10 \mathrm{~Hz}$, respectively). It was observed that approximately half of the STN neurons examined displayed a period of inhibition lasting up to several hundred milliseconds after high frequency stimulation. Detailed results of the responses of STN neurons to local stimulation have been reported previously (15).

\section{DISCUSSION}

This study compared the use of two closely spaced, independently controlled microelectrodes with the standard single microelectrode technique for the localization of the STN in PD patients. A practical advantage of this setup is that the second microelectrode can be used as a backup when there are concerns regarding microelectrode reliability (approximately $7 \%$ of microelectrode tracks in our group of 52 dual technique patients). This result suggests that standard single microelectrode mapping can run the risk of providing false-negative results as marked by a low signal-to-noise ratio or acellularity in as many as $7 \%$ of the trajectories explored (i.e., guide tube penetrations). It should be noted that the surgeon was not committed to using both microelectrodes and could, therefore, explore trajectories using just one microelectrode if desired. However, in

TABLE 1. Comparison of similar findings to dissimilar findings between the two microelectrodes with the dual microelectrode technique ${ }^{a}$

Dorsal border of STN

Total no. of trajectories

Borders identified by both microelectrodes

Borders not identified by either microelectrode

Total percentage of similar findings

Border only identified with S1

Border only identified with S2

Total percentage of dissimilar findings ${ }^{b}$
Ventral border of STN

Dorsal border of $\mathrm{SNr}$

101
77
19
95
3
2
$5 \%$

77

19

$95 \%$

3

2

$5 \%$

$\begin{array}{lc}98 & 98 \\ 74 & 56 \\ 20 & 21 \\ 96 \% & 79 \%\end{array}$

2

2

$4 \% \quad 21 \%$

a STN, subthalamic nucleus; $\mathrm{SNr}$, substantia nigra pars reticulata; $\mathrm{S} 1$, right-sided guide tube; $\mathrm{S} 2$, left-sided guide tube.

${ }^{b}$ Total percentage of instances in which there was disagreement between the two microelectrodes in a single trajectory (i.e., a border was found on one microelectrode but not the other). 
A

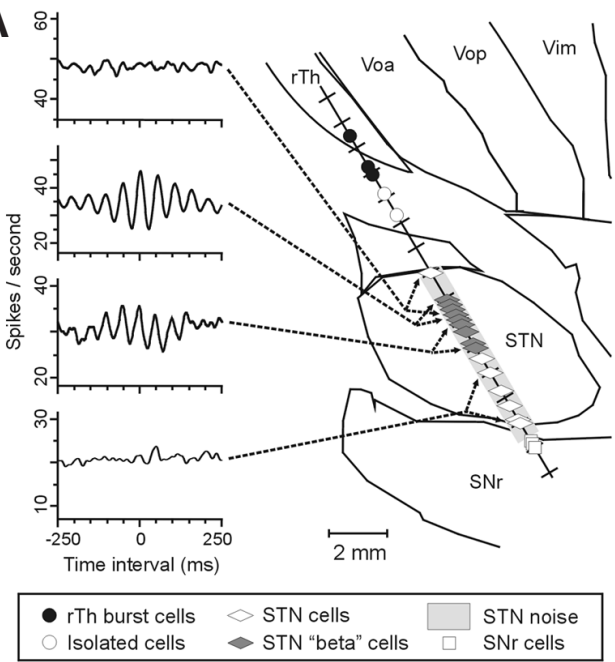

STN $20 \mathrm{~Hz}, 200 \mathrm{uA}$

B
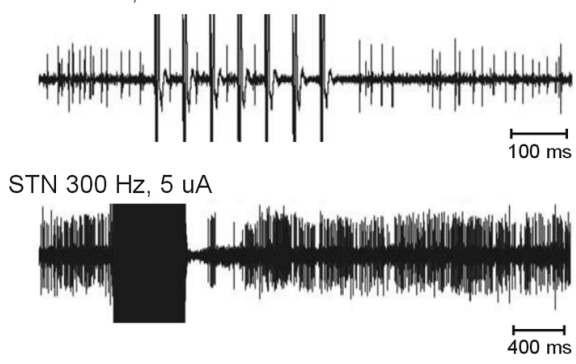

$\mathrm{SNr} 10 \mathrm{~Hz}, 80 \mathrm{uA}$
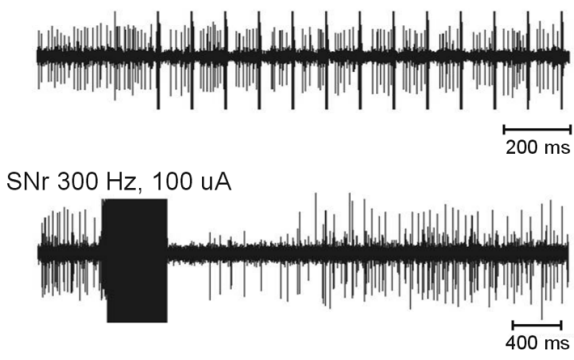

FIGURE 3. Dual neuron crosscorrelation and microstimulation recording. A, cross-correlograms of four neuron pairs in a single patient (width, $5 \mathrm{~ms}$ ). The second and third cross-correlograms demonstrate the presence of population activity with synchronized in-phase $20 \mathrm{~Hz}$ oscillations in a group of dorsal STN neurons. Neurons were sampled for 30 seconds. B, simultaneous microstimulation from one microelectrode and recording from the other in the STN and SNr of four patients. Large spikes in low frequency stimulation trials and black rectangles are due to the stimulus artifacts and indicate the times of occurrence of the single stimuli and high frequency stimulation trains. Microelectrodes were approximately $600 \mu \mathrm{m}$ apart in each case. Burst cells, cells firing in short bursts characteristic thalamic low threshold calcium spike-mediated bursts; rTh, reticular thalamus; STN, subthalamic nucleus; STN $\beta$ cells, individual STN neurons that display 13 to $30 \mathrm{~Hz}$ oscillations; STN noise, increase in background multiunit activity recorded from individual microelectrodes; $\mathrm{SNr}$, substantia nigra pars reticulata; Voa, nucleus ventralis oralis anterior; Vop, nucleus ventralis oralis posterior; Vim, ventrointermedius. many instances, the availability of a second microelectrode in the same trajectory was certainly very helpful. The second microelectrode also serves to confirm and better delineate electrophysiological landmarks such as the dorsal and ventral borders of the STN. The use of dual recordings helped to confirm the presence or absence of STN borders in $95 \%$ of the trajectories performed. The median values for the distance of the final dorsal and ventral borders of the STN from the initial dorsal-ventral target location are consistent with a report by Hamani et al. (18) and with the prediction based on the location of the predicted target for the electrode track within the STN. However, as shown in Figure $2 A$, there is a considerable spread in the distances of borders from the initial targets. Values markedly different from the median indicate a considerable discrepancy between the MRI and atlas map prediction, and the microelectrode exploration findings and may be related to imaging distortions and brain structure variability. In a series of 12 patients, Zonenshayn et al. (49) demonstrated an average distance error of approximately $4 \mathrm{~mm}$ between the final physiological targets and the MRI-derived targets, which is considerably larger than that found in our study. In our study, when borders were found on both microelectrodes, they were separated in the dorsal-ventral direction by usually less than $0.7 \mathrm{~mm}$ irregardless of the distance from the initial MRI target. A second closely spaced microelectrode reassures the surgeon of the quality of the information obtained, improves the efficiency of the procedure, and may reduce the need for more trajectories.

There was a significant decrease in the number of trajectories needed to localize the STN from a median of three to two when dual microelectrode recordings were used. The decrease in the number of trajectories may be attributable to an increased confidence in the quality of the sampled single neurons in each trajectory, the decrease in the effects of unreliable recordings, and the improved delineation of nuclear borders. However, a possible drawback of this technique is that an extra microelectrode track is made through the STN for each explored trajectory so that the number of electrode tracks is actually higher (median, four versus three). A reduction in the number of electrode tracks is important because microelectrode recording techniques are not without the risk of severe complications $(6,13,20,21)$; thus, there is an impetus to reduce the number of these invasive trajectories $(10,16)$. However, the incidence of symptomatic postoperative hemorrhage using the dual microelectrode technique was 1 to $2 \%$, which is in the same range reported in a recent review of the literature (19). An approach we have demonstrated in this article is to maximize the neuronal data obtained from each trajectory. A caveat is that the reduction in the number of trajectories needed to localize the STN may be confounded by the learning curve, in which the general trend is to perform fewer trajectories with increasing experience (see solid and dashed lines in Figure 2D). However, as shown in Figure 2D, the learning curves for either technique reached a plateau after approximately 25 patients, suggesting that the use of dual recordings can further reduce the number of trajectories. Lastly, commercially available systems incorporating multiple simultaneous recording schemes (Alpha Omega MicroGuide Pro sys- AQ:3 
tem [Alpha Omega Co., Alpharetta, GA], Medtronic Leadpoint system [Medtronic, Inc., Minneapolis, MN], FHC microTargeting Drive System with maTrix Mount [FHC, Inc., Bowdoinham, ME], Inomed ISIS MER system [Teningen, Germany]) incorporate a multichannel array comprising five separate fixed guide tubes that are spaced $2 \mathrm{~mm}$ apart and arranged in a cruciate pattern. This configuration commits the surgeon to perform five trajectories. It has been noted that only two or three of the five microelectrodes usually provide for STN localization (5).

The analysis of neuronal firing rates and patterns in the STN of patients with PD provides us with an opportunity to characterize pathophysiological activity such as tremor-related activity $(23,31,36,37,44)$ and somatosensory responses $(1,14,30$, $45)$. The use of dual microelectrode recordings allows for the correlation of spiking activity of neurons separated by $600 \mu \mathrm{m}$ to $20 \mathrm{~mm}$, thereby permitting analysis of local and widespread population activity. The characterization of population activity involves the correlation of neuronal discharge and can be used to extract information regarding neuronal physiological states that is not available from single neuron data. The importance of correlated population activity has been highlighted in the basal ganglia of patients with PD (7-9, 22, 29, 31, 41). Individual STN neurons may display oscillatory discharge activity in the $\beta$ band frequency range of 13 to $30 \mathrm{~Hz}$. When crosscorrelated, closely spaced pairs of these neurons show an in-phase oscillatory population activity that is more synchronized in the dopamine depleted state (see Figure 3A). This synchronized activity has also been shown to decrease with movement $(4,28)$. These changes in neuronal activity can be detected $(25,28)$ in a reduction of the $\beta$ frequency spectral power of LFPs recorded from the DBS electrodes $(8,12,28,43)$. The clinical relevance of these findings is that DBS at sites displaying these pathological $\beta$ frequency range LFP oscillations produces the most effective motor benefit in patients with PD (38). Therefore, the ability to identify areas in the STN through the correlation of pairs of neurons or indirectly through LFP recordings may lead to the optimization of DBS parameters in both intra- and postoperative scenarios.

The dual microdrive head stage assembly can also be used to characterize neuronal responses to microstimulation and, similarly, macrostimulation by replacing one of the electrodes with a cannula. We have previously shown that there are characteristic patterns of neuronal inhibition in subgroups of STN and GPi neurons $(11,15)$. The information provided can be used as an aid for identification of these structures in conjunction with neuronal recording and the clinical effects of stimulation. Lastly, the thin cannula allows for the local injection of pharmacological agents. A local reversible anesthetic block using 5 to $10 \mu \mathrm{l}$ of $2 \%$ lidocaine can mimic the effects of DBS and lesions in the STN of patients with PD; the spread of drugs can be monitored by simultaneously recording neural activity at a short distance from the injection cannula (32). This method can, therefore, facilitate the subsequent placement of permanent lesions in the STN $(3,40)$ to predict lesion outcome in a reversible manner.
In summary, we have demonstrated the utility of closelyspaced dual microelectrode recordings to improve STN localization by increasing the amount of relevant functional data per trajectory, decreasing the effects of unreliable recordings and improving the delineation of nuclear borders. These features may be reflected as a decrease in the number of trajectories required to adequately localize the STN. The ability to examine synchronized population activity by correlating the discharge of closely spaced individual neurons has also substantially increased our knowledge of basal ganglia pathophysiology and may be used as an additional tool to localize the STN in conjunction with LFP recordings, simultaneous recording with micro- or macrostimulation, and local drug injection. A future research focus will be to correlate the use of dual electrode techniques to patient outcome such as the efficacy of DBS or lesions targeted at specific pathological activity.

\section{REFERENCES}

1. Abosch A, Hutchison WD, Saint-Cyr JA, Dostrovsky JO, Lozano AM: Movement-related neurons of the subthalamic nucleus in patients with Parkinson disease. J Neurosurg 97:1167-1172, 2002.

2. Alterman RL, Sterio D, Beric A, Kelly PJ: Microelectrode recording during posteroventral pallidotomy: Impact on target selection and complications. Neurosurgery 44:315-323, 1999.

3. Alvarez L, Macias R, Guridi J, Lopez G, Alvarez E, Maragoto C, Teijeiro J, Torres A, Pavon N, Rodriguez-Oroz MC, Ochoa L, Hetherington H, Juncos J, DeLong MR, Obeso JA: Dorsal subthalamotomy for Parkinson's disease. Mov Disord 16:72-78, 2001.

4. Amirnovin R, Williams ZM, Cosgrove GR, Eskandar EN: Visually guided movements suppress subthalamic oscillations in Parkinson's disease patients. J Neurosci 24:11302-11306, 2004.

5. Benazzouz A, Breit S, Koudsie A, Pollak P, Krack P, Benabid AL: Intraoperative microrecordings of the subthalamic nucleus in Parkinson's disease. Mov Disord 17 [Suppl 3]:S145-S149, 2002.

6. Binder DK, Rau GM, Starr PA: Risk factors for hemorrhage during microelectrode-guided deep brain stimulator implantation for movement disorders. Neurosurgery 56:722-732, 2005.

7. Brown P, Oliviero A, Mazzone P, Insola A, Tonali P, Di Lazarro V: Dopamine dependency of oscillations between subthalamic nucleus and pallidum in Parkinson's disease. J Neurosci 21:1033-1038, 2001.

8. Cassidy M, Mazzone P, Oliviero A, Insola A, Tonali P, Di Lazzaro V, Brown P: Movement-related changes in synchronization in the human basal ganglia. Brain 125:1235-1246, 2002.

9. Cassim F, Labyt E, Devos D, Defebvre L, Destee A, Derambure P: Relationship between oscillations in the basal ganglia and synchronization of cortical activity. Epileptic Disord 4 [Suppl 3]:S31-S45, 2002.

10. Deep-Brain Stimulation for Parkinson's Disease Study Group: Deep brain stimulation of the subthalamic nucleus or the pars interna of the globus pallidus in Parkinson's disease. N Engl J Med 345:956-963, 2001.

11. Dostrovsky JO, Levy R, Wu JP, Hutchison WD, Tasker RR, Lozano AM: Microstimulation-induced inhibition of neuronal firing in human globus pallidus. J Neurophysiol 84:570-574, 2000.

12. Doyle LM, Kuhn AA, Hariz M, Kupsch A, Schneider GH, Brown P: Levodopa-induced modulation of subthalamic beta oscillations during selfpaced movements in patients with Parkinson's disease. Eur J Neurosci 21:1403-1412, 2005.

13. Favre J, Taha JM, Burchiel KJ: An analysis of the respective risks of hematoma formation in 361 consecutive morphological and functional stereotactic procedures. Neurosurgery 50:48-57, 2002.

14. Fawcett AP, Dostrovsky JO, Lozano AM, Hutchison WD: Eye movementrelated responses of neurons in human subthalamic nucleus. Exp Brain Res 162:357-365, 2005 
15. Filali M, Hutchison WD, Palter VN, Lozano AM, Dostrovsky JO: Stimulationinduced inhibition of neuronal firing in human subthalamic nucleus. Exp Brain Res 156:274-281, 2004.

16. Gorgulho A, De Salles AA, Frighetto L, Behnke E: Incidence of hemorrhage associated with electrophysiological studies performed using macroelectrodes and microelectrodes in functional neurosurgery. J Neurosurg 102:888-896, 2005.

17. Guridi J, Gorospe A, Ramos E, Linazasoro G, Rodriguez MC, Obeso JA: Stereotactic targeting of the globus pallidus internus in Parkinson's disease: Imaging versus electrophysiological mapping. Neurosurgery 45:278-289, 1999.

18. Hamani C, Richter EO, Andrade-Souza Y, Hutchison W, Saint-Cyr JA, Lozano AM: Correspondence of microelectrode mapping with magnetic resonance imaging for subthalamic nucleus procedures. Surg Neurol 63:249-253, 2005.

19. Hamani C, Richter E, Schwalb JM, Lozano AM: Bilateral subthalamic nucleus stimulation for Parkinson's disease: a systematic review of the clinical literature. Neurosurgery 56:1313-1324, 2005.

20. Hariz MI, Fodstad H: Do microelectrode techniques increase accuracy or decrease risks in pallidotomy and deep brain stimulation? A critical review of the literature. Stereotact Funct Neurosurg 72:157-169, 1999

21. Higuchi Y, Iacono RP: Surgical complications in patients with Parkinson's disease after posteroventral pallidotomy. Neurosurgery 52:558-571, 2003.

22. Hurtado JM, Gray CM, Tamas LB, Sigvardt KA: Dynamics of tremor-related oscillations in the human globus pallidus: A single case study. Proc Natl Acad Sci U S A 96:1674-1679, 1999.

23. Hutchison WD, Allan RJ, Opitz H, Levy R, Dostrovsky JO, Lang AE, Lozano AM: Neurophysiological identification of the subthalamic nucleus in surgery for Parkinson's disease. Ann Neurol 44:622-628, 1998.

24. Hutchison WD, Lozano AM, Davis KD, Saint-Cyr JA, Lang AE, Dostrovsky JO: Differential neuronal activity in segments of globus pallidus in Parkinson's disease patients. Neuroreport 5:1533-1537, 1994.

25. Kuhn AA, Trottenberg T, Kivi A, Kupsch A, Schneider GH, Brown P: The relationship between local field potential and neuronal discharge in the subthalamic nucleus of patients with Parkinson's disease. Exp Neurol 194:212-220, 2005.

26. Lenz FA, Dostrovsky JO, Kwan HC, Tasker RR, Yamashiro K, Murphy JT: Methods for microstimulation and recording of single neurons and evoked potentials in the human central nervous system. J Neurosurg 68:630-634, 1988

27. Lenz FA, Tasker RR, Kwan HC, Schnider S, Kwong R, Murayama Y, Dostrovsky JO, Murphy JT: Single unit analysis of the human ventral thalamic nuclear group: Correlation of thalamic "tremor cells" with the 3-6 Hz component of parkinsonian tremor. J Neurosci 8:754-764, 1988.

28. Levy R, Ashby P, Hutchison WD, Lang AE, Lozano AM, Dostrovsky JO: Dependence of subthalamic nucleus oscillations on movement and dopamine in Parkinson's disease. Brain 125:1196-1209, 2002.

29. Levy R, Davis KD, Hutchinson WD, Pahapill PA, Lozano AM, Tasker RR, Dostrovsky JO: Simultaneously recorded neuron pairs in the motor thalamus of patients with Parkinson's disease and essential tremor. Soc Neurosci Abstr 25:1408, 1999 (abstr).

30. Levy R, Dostrovsky JO, Lang AE, Sime E, Hutchison WD, Lozano AM: Effects of apomorphine on subthalamic nucleus and globus pallidus internus neurons in patients with Parkinson's disease. J Neurophysiol 86:249-260, 2001.

31. Levy R, Hutchison WD, Lozano AM, Dostrovsky JO: High-frequency synchronization of neuronal activity in the subthalamic nucleus of parkinsonian patients with limb tremor. J Neurosci 20:7766-7775, 2000.

32. Levy R, Lang AE, Dostrovsky JO, Pahapill P, Romas J, Saint-Cyr J, Hutchison WD, Lozano AM: Lidocaine and muscimol microinjections in subthalamic nucleus reverse Parkinsonian symptoms. Brain 124:2105-2118, 2001.

33. Linhares MN, Tasker RR: Microelectrode-guided thalamotomy for Parkinson's disease. Neurosurgery 46:390-398, 2000.

34. Lozano AM, Hutchison WD, Dostrovsky JO: Microelectrode monitoring of cortical and subcortical structures during stereotactic surgery. Acta Neurochir Suppl 64:30-34, 1995

35. Lozano A, Hutchison W, Kiss Z, Davis K, Dostrovsky J: Methods for microelectrode-guided posteroventral pallidotomy. J Neurosurg 84:194-202, 1996

36. Magarinos-Ascone CM, Figueiras-Mendez R, Riva-Meana C, CordobaFernandez A: Subthalamic neuron activity related to tremor and movement in Parkinson's disease. Eur J Neurosci 12:2597-2607, 2000.
37. Magnin M, Morel A, Jeanmonod D: Single-unit analysis of the pallidum, thalamus and subthalamic nucleus in parkinsonian patients. Neuroscience 96:549-564, 2000

38. Marsden JF, Limousin-Dowsey P, Ashby P, Pollak P, Brown P: Subthalamic nucleus, sensorimotor cortex and muscle interrelationships in Parkinson's disease. Brain 124:378-388, 2001.

39. Molinuevo JL, Valldeoriola F, Rumia J, Nobbe FA, Martinez R, Ferrer E, Tolosa E: Contribution of neurophysiological guidance to stereotactic posteroventral pallidotomy for Parkinson's disease. Acta Neurochir (Wien) 141:1195-1201, 1999.

40. Patel NK, Heywood P, O'Sullivan K, McCarter R, Love S, Gill SS: Unilateral subthalamotomy in the treatment of Parkinson's disease. Brain 126:1136-1145, 2003.

41. Patil PG, Carmena JM, Nicolelis MA, Turner DA: Ensemble recordings of human subcortical neurons as a source of motor control signals for a brainmachine interface. Neurosurgery 55:27-38, 2004

42. Priori A, Egidi M, Pesenti A, Rohr M, Rampini P, Locatelli M, Tamma F, Caputo E, Chiesa V, Barbieri S: Do intraoperative microrecordings improve subthalamic nucleus targeting in stereotactic neurosurgery for Parkinson's disease? J Neurosurg Sci 47:56-60, 2003.

43. Priori A, Foffani G, Pesenti A, Bianchi A, Chiesa V, Baselli G, Caputo E, Tamma F, Rampini P, Egidi M, Locatelli M, Barbieri S, Scarlato G: Movementrelated modulation of neural activity in human basal ganglia and its L-DOPA dependency: Recordings from deep brain stimulation electrodes in patients with Parkinson's disease. Neurol Sci 23 [Suppl 2]:S101-S102, 2002.

44. Rodriguez MC, Guridi OJ, Alvarez L, Mewes K, Macias R, Vitek J, DeLong MR, Obeso JA: The subthalamic nucleus and tremor in Parkinson's disease. Mov Disord 13 [Suppl 3]:111-118, 1998.

45. Rodriguez-Oroz MC, Rodriguez M, Guridi J, Mewes K, Chockkman V, Vitek J, DeLong MR, Obeso JA: The subthalamic nucleus in Parkinson's disease: Somatotopic organization and physiological characteristics. Brain 124:1777-1790, 2001.

46. Schaltenbrand G, Wahren W: Atlas for Stereotaxy of the Human Brain. Stuttgart, AQ:4 Georg Thieme, 1977.

47. Sterio D, Zonenshayn M, Mogilner AY, Rezai AR, Kiprovski K, Kelly PJ, Beric A: Neurophysiological refinement of subthalamic nucleus targeting. Neurosurgery 50:58-69, 2002

48. Vitek JL, Bakay RA, Hashimoto T, Kaneoke Y, Mewes K, Zhang JY, Rye D, Starr P, Baron M, Turner R, DeLong MR: Microelectrode-guided pallidotomy: Technical approach and its application in medically intractable Parkinson's disease. J Neurosurg 88:1027-1043, 1998.

49. Zonenshayn M, Rezai AR, Mogilner AY, Beric A, Sterio D, Kelly PJ: Comparison of anatomic and neurophysiological methods for subthalamic nucleus targeting. Neurosurgery 47:282-294, 2000.

\section{Acknowledgments}

Funding was provided by the Canadian Institutes of Health Research FRN: 42505 and the United States National Institutes of Health RO1 nanoseconds 40872. Andres M. Lozano, M.D., Ph.D., is a Canadian Institutes of Health Research clinician scientist. 